\title{
What Is It Like To Be IMmortal?
}

\author{
- Joseph Ulatowski -
}

\begin{abstract}
The idea of an eternal and immortal life like the one we lead now seems quite appealing because (i) it will be sufficiently like our own earth-bound life and (ii) we will have the same kinds of desires we have now to want to live an eternal life. This paper will challenge the view that we have a conception of what the conscious experience of an immortal is like, regardless of whether we might want to live it. Given that for us to conceive of an immortal life we must project onto it our own view of what it is like to live our own life, and given that an immortal life may not be anything like the life we live, we cannot conceive of what it is like to be immortal.
\end{abstract}

Keywords: metaphysics, death, immortality, phenomenology, consciousness.

Published online: 10 December 2019

An immortal life seems quite appealing for us mortals. The pollyannaish thought that we could live a life like our own for an infinite amount of time increases the likelihood that our life would be filled with tremendous joy and happiness. The unhappiness and disutility of any single moment would be greatly overshadowed by moments of unspeakable and incalculable moments of bliss. The sadness and heartache of losing loved ones, close friends, siblings, and parents would be forevermore mere fantasy.

The aim of this paper is to argue that we are not in a good epistemic position to judge what the subjective experiences of an immortal would be like. The thought that we would desire to live a life for 100,000 years, or even 1,000,000 years, is based upon a prejudice in favour of our actual physical and psychological condition persisting into the hereafter. If it turns out that our prejudice in favour of our actual life and all of its accompanying psychological conditions fails to discriminate fact from fiction, then we would have no reason to think we are able to conceive of who we will become. Given that for us to conceive of an immortal life we must project onto it our own view of what it is like to live our own life and given that the experiences of an immortal life may not be anything like the life we live, we cannot conceive of what it is like to be immortal. Along the way, I will have to consider some potential objections to this position. In conclusion, the thought that I would prefer an immortal life cannot be entertained by us, since we have no idea what the experience of that future living thing would be.

Joseph Ulatowski

Division of Arts, Law, Psychology \& Social Sciences

University of Waikato

Private Bag 3105, Gate 1, Knighton Road, Hamilton 3240, New Zealand

email: joe.ulatowski@waikato.ac.nz 


\section{Conditions and Definitions}

Prior to setting out an argument showing that we cannot judge whether an immortal life is desirable, some space should be dedicated to the background conditions that the argument assumes to be true. These background conditions follow those set out by Bernard Williams in his landmark paper: "The Makropulos Case: Reflections on the Tedium of Immortality," ${ }^{2}$ and by others, such as Donald Bruckner, ${ }^{3}$ Jay Rosenberg, ${ }^{4}$ and Hunter Steele. $^{5}$

Let us begin by noting that the argument for showing that we are not in a good epistemic position to judge whether an immortal life is desirable depends upon a thought experiment that elicits a judgment about the concept of 'immortality'. The thought experiment presented here will ask us to determine whether we know what it would be like to live the life of an immortal. Since we are not immortals ourselves and since we have no justificatory evidence from other immortals, we ultimately cannot know what it would be like to be immortal. One might note that the thought experiment presented in this paper seems to exploit the foci of realist phenomenology. Realist phenomenology has focused upon the essence of God and the essence of human persons. God and humans share in personhood, but human personhood is finite and God's divine personhood is infinite. ${ }^{6}$

To consider the argument for or against the desirability of an immortal life, we must assume that the universe as we know it will never cease to exist in a physical state other than in its current physical state. Despite what our best science tells us, i.e., that the universe eventually will cool and collapse in upon itself or contract back in on itself obliterating everything from existence, what we assume for this argument is that the universe immortals colonize is a world without end. There is no end to time, and the world as we have come to know it will continue to exist exactly as we have come to know it. ${ }^{7}$ That the physical universe remains in its current state suggests that the body-bound immortal must remain in its current state, too.

There are different definitions of 'immortality', but the one discussed here is a body-bound, or 'punctuated', immortality. It is a limited embodied form of everlasting life where we retain our own body at a predefined physical time period and inhabit that physical form for an indefinite or unbounded amount of time. ${ }^{8}$ The punctuated immortal life is one lived in a physical body that does not age or physically deteriorate. Despite the lack of change to one's physical characteristics, it is supposed that a person's psychological or mental life would continue to evolve.

\footnotetext{
${ }^{2}$ Williams (1973).

${ }^{3}$ Bruckner (2012).

${ }^{4}$ Rosenberg (2006).

${ }^{5}$ Steele (1976).

${ }^{6} \mathrm{I}$ thank a reviewer for pointing out that some elements of realist phenomenology may be relevant to this paper. However, it should be noted that I am not a phenomenologist. See Mezei (2017) or Smith (1997) for helpful discussions of realist phenomenology.

${ }^{7}$ Of the assumptions one must adopt to entertain the desirability of immortal life, this is likely the most controversial one. Naturalists will reject the idea that the universe could exist in its current form for an eternity.

${ }^{8}$ Cf. Bruckner (2012): 626; Rosenberg (2006): 228.
} 
That the person would remain a physical age, such as the age of 42 , is completely random. Any way that one would like to conceive of the age of the punctuated immortal will suffice for the example to work. If one prefers the age of 25 over the age of 42 , then so be it. The age of the person seems to make no difference. It is not beyond the example for one to inhabit the physical body of a 72 year-old or a 15 year-old, though the person may be subject to certain biases or prejudices of others that go along with being elderly or adolescent. ${ }^{9}$

The punctuated immortal life does not come without its limitations. Among its most salient limitations is the immortal's susceptibility to death by human cause. Should the person choose to jump from the Empire State Building or run in freeway traffic, the person will die from injuries sustained by what one would expect when leaping from tall buildings or playing in traffic. Likewise, immortals could mortally wound other immortals, whether by shooting, stabbing, poisoning, or beating another to death.

Moreover, following Williams, the person will have to drink an elixir every three hundred years. ${ }^{10}$ The immortal life does not come without consequence. If the person fails to drink the elixir at the designated 300-year interval, then the person's life will come to an end. This permits the immortal to become mortal again. If the person becomes bored by the life she's leading, then she can choose to end it without involving oneself or others in some sort of potentially criminal activity.

\section{The Makropulos Case}

In this section, I summarise Bernard Williams' dilemma, setting up the next section wherein I argue that what it is to be immortal can only be understood if one is immortal. Our finding an immortal life appealing depends upon our having an appreciation of the subjective qualitative states that accompany an immortal life.

Williams has argued that an immortal life must satisfy two conditions to eschew acute boredom: (i) the future person must be identical to the person as they are now, and (ii) the life of the immortal must be attractive to the person as they are now. ${ }^{11}$ The two conditions imply a dilemma: either the body-bound immortal will remain psychologically the same as the mortal or one's psychological disposition will change (and perhaps radically so). If the immortal remains the same as the mortal, then the desire to continue living will decrease and the person will eventually wish not to be immortal. If the person's psychological disposition changes, then the mortal will not believe immortality to be desirable because the immortal will become someone very different from the mortal one is now. By way of illustration, Williams presents the case of Elina Makropulos (hereafter 'EM') from The Makropoulus Secret. EM possesses an elixir, a single dose of which is capable of extending her life by three hundred years with no physical

\footnotetext{
${ }^{9}$ In other words, if other immortals are eternally 35 and human prejudices carry over to the immortal life, e.g., ageism, then the 72-year-old may have to confront the uncomfortable realisation that that physical body of the punctuated immortal body matters to other immortals when it comes to hiring or mating decisions.

${ }^{10}$ Williams (1973): 82-84.

${ }^{11}$ Williams (1973).
} 
signs of ageing. When we first encounter her, she is 342 years old, having taken a single dose at the biological age of 42, and is contemplating whether to drink the elixir another time. Williams tells us that EM's life has become boring, indifferent, and cold. ${ }^{12}$ So, EM now has no stake in seeing to it that the future person she would become in the case of consuming the elixir should come to pass. Given the outcome of EM, it looks very bad for choosing to live any longer than we absolutely must. ${ }^{13}$

Williams argued that a punctuated immortal life with infinitely many relevantly similar experiences would be an insufferably tedious one that would not be worth living, and for which it is not at all unreasonable to end. If one has a desire for immortality, then it likely comes about because of a desire for a free and open future, to do what one wants to do and to go on living. It is not that we have incomplete information about such a future as an immortal but that we cannot imagine what sort of beings we would be in it. ${ }^{14}$ So, rather than focus upon whether or not an infinite life is worth living or even appealing to us now, I endeavour to challenge a prevailing assumption of Williams, and others who work in this area, that the subjective qualitative phenomenological experiences of the immortal is sufficiently similar to our own. ${ }^{15}$ If the qualitative experiences of one's mortal self and one's immortal self are sufficiently dissimilar, then we fail to be in a position to compare the two.

The next section discusses further the subjective phenomenal character of experience and why we ought to think that we cannot extend it to organisms and entities, including body-bound immortals, because we are not even vaguely familiar with the kind of experience these things might have.

\section{The Argument}

The literature on immortality typically begins with the intuition that we would want to live a life like ours for an eternity. Although we are intimately familiar with our own life and our own lived experiences, we seem to assume that the phenomenology of sensory experience will not appreciate or depreciate over an infinite amount of time. The immortal's sensory experience would not differ substantially in any way from our own sensory experience, but this seems to neglect that the mortal life is transitory in a way that an immortal life would not be. In this section, I will argue that one cannot decipher

\footnotetext{
${ }^{12}$ Changing the parameters of the EM example yields a change in one's response to the case. For example, if the physical body did not remain intact at the age of 42 or if the mental life of the individual began to deteriorate in any way, we might find the case less appealing.

${ }^{13}$ In another paper, Beisecker and Ulatowski (unpublished $\mathrm{ms}$ ) have argued that living a body-bound immortal life would not only become chronically boring but also living an immortal life would provide us with ample time to solve all of the pressing questions we would ever want to resolve and exhaust all realms of science, thus leaving us, scientists included, twiddling our thumbs for an eternity. The thought of such boredom would be too much for any one of us to take, and we would choose to take our own life.

${ }^{14}$ Roman Altshuler (2015) has a profound discussion of what role conative states play in immortality, and Jay Rosenberg (2006) has a nice summary showing what is unknown about immortality makes its openness so desirable.

${ }^{15}$ Cf. Bortolotti and Nagasawa (2009); Bostrom (2008); Bruckner (2012); Chappell (2007); Fischer

(1994, 1997); Gems (2003); Johnston (2010); Preston (2007).
} 
what it is like to be immortal, even if, rather naively, we believe the experiences of an immortal seem overwhelmingly like our own mortal experiences.

My main argument should reflect the influence of Thomas Nagel's famous bat case ${ }^{16}$ We should remember that Nagel argued that the subjective character of the conscious experience of a bat, i.e., the 'what-it-is-like' component of consciousness, is something we (non-bats) cannot conceive. To begin with, we have to characterise the subjective character of phenomenal experience.

The subjective character of phenomenal experience is the "what-it-is-like" experience we have of the world around us. According to Nagel,

Conscious experience is a widespread phenomenon. ... [N]o matter how the form may vary, the fact that an organism has conscious experience at all means, basically, that there is something it is like to be that organism. ... [A]n organism has conscious mental states if and only if there is something that it is like to be that organism - something it is like for the organism. ${ }^{17}$

To be conscious is to have particular sensations and experiences, and these cognitive states are specifically restricted to one's own experience. There is no way for any agent to perceive what another agent encounters through the five sensory modalities. To believe that conscious experience is ubiquitous enough for any one person to have the very same sensations as any other person is to confuse experience with something like empathy. ${ }^{18}$

David Chalmers, among others, followed on Nagel's analysis of the qualitative states associated with our conscious experience. For him - like Nagel before him - Chalmers believes that consciousness is utterly mysterious, but contends that the subjective phenomenal part of it presents us with a 'hard problem'. His notion of consciousness has it that:

[I]t is at once the most familiar thing in the world and the most mysterious. There is nothing we know about more directly than consciousness, but it is far from clear how to reconcile it with everything else we know. ... We know consciousness far more intimately than we know the rest of the world, but we understand the rest of the world far better than we understand consciousness.

\section{$[\ldots]$}

The subject matter [of consciousness] is perhaps best characterised as "the subjective quality of experience." When we perceive, think, and act, there is a whir of causation and information processing, but this processing does not usually go on in the

\footnotetext{
${ }^{16}$ Nagel (1979).

${ }_{17}$ Nagel (1979): 166.

${ }^{18}$ I will not have the space in this paper to discuss the overlapping similarities between consciousness and empathy, though one can readily see how an agent might confuse the two. Whereas empathy is something we can have for others and their experiences, it is not to presume that we have exactly the same sensations. After all, we are not them, and they are not us.
} 
dark. There is also an internal aspect; there is something it feels like to be a cognitive agent. This internal aspect is conscious experience. Conscious experiences range from vivid colour sensations to experiences of the faintest background aromas; from hard-edged pains to the elusive experience of thoughts on the tip of one's tongue; from mundane sounds and smells to the encompassing grandeur of musical experience; from the triviality of a nagging itch to the weight of a deep existential angst; from the specificity of the taste of peppermint to the generality of one's experience of selfhood. All these have a distinct experienced quality. All are prominent parts of the inner life of the mind. ${ }^{19}$

The inner life of the mind is the something it is like to be human. It is the qualitative feel associated with having some experience and being in that particular mental state.

So, the subjective character of phenomenal experience or qualia of conscious experience is something with which we are intimately familiar. We can readily see that one thing we have in common with other organisms of our species is our conscious experience. The question is whether we can argue that other organisms, i.e., those outside our own species, have this subjective character of phenomenal experience.

There is no doubt that other organisms have some kind of sensory experience. We need only observe ants navigating around obstacles to realise that they must have some kind of sensory experience. Species closer to our own, like chimpanzees, seem to have subjective phenomenal conscious experience closer to our own than the conscious experience of ants. It seems that way to us because of our overwhelming desire to say that entities which resemble us must have a similar form of conscious experience.

Species unlike us, such as ants, do not resemble us and, hence, likely do not have conscious experience like us. Instead of ants, Nagel, for example, chose to contrast our conscious experience with the sensory experience of bats. This is not likely a coincidental choice on Nagel's part. Bats are unique because their primary way of interacting with the world is through echolocation. Since we do not navigate the world using echolocation, it makes us as a species an unlikely candidate to recognise the conscious experience of bats. We do not know what it is like to be a bat. The subjective character of experience is unrecognisable by us given the dissimilarities between the two species.

If we cannot extrapolate to the case of other organisms, e.g., bats, then there seems reason to deny that we can know what it is like to be that other organism. The case of conceiving what it is like to be a bat or ant or bacteria seems like something we cannot possibly understand. The species are just too distantly related to our own for us to have a clear way of judging whether our own experience overlaps with theirs. But one might argue immortal humans are closely related to us. They are not another species; they are our own species in an alternative form. So, it seems ridiculous to believe that we cannot form a conception of what it is like to be an immortal.

The view that we are able to conceive of what it is like to be immortal rests upon a mistake. While we are capable of conceiving the possibility of an immortal life, permanent, unending and unchanging, we are not well placed to conceive of what it

${ }^{19}$ Chalmers (1996): 3. 
is like to be such an entity that is so permanent. An immortal, even one bound to a human body, is something that lasts forever. The immortal life is missing a sense of closure, the possibility of death, that enables us to derive a sense of worth and meaning for having completed individual projects. ${ }^{20}$ Mortals will not last forever, so the narrative arc of our own mortal lives depends upon life's fleetingness. Memories might fade and desires rejuvenate over the course of an immortal life, but the property of "living forever" and the immutability of immortal life is so vastly different from our own transiency that we are incapable of conceiving what it is like to be immortal. Because we lack a property that immortals have, we can say not only that our conscious experiences differ from their immortal conscious experience but that we are different. Given the substantial difference between human mortals and human immortals, we cannot conceive of what it is like to be an immortal (despite that we might think we comprehend the experiences we have as mortals and that these experiences carryover to immortality).

Our bodies are structurally quite distinct, too. The physical constitution of an immortal "body," especially in how it is attained through the elixir, necessarily implies that material composition of an immortal is fundamentally different than that of the mortal human body. We must not forget that human beings have been endowed with bodily physiological functions that are necessary for a healthy bodily life. For example, the digestive system of a human consists of the mouth, esophagus, stomach, gastrointestinal tract, liver, pancreas, gall bladder, and salivary glands. Some humans suffer biliary dyskinesia when the gallbladder does not empty bile correctly. This would prompt a doctor to remove the gallbladder. The function of the gallbladder has deteriorated over the course of the person's life. The so-called immortal's body would not undergo such change. The immortal body is fundamentally different from the mortal one, not just at the macro-level but at the molecular or cellular level. Even if the immortal were human-like in appearance, the body of the immortal would be so different from mortal that the two would be different kinds of being.

Recently, Laurie Paul has argued that one cannot make a rational decision about whether to have children on the basis of what it will be like to have them because the experience of having children is transformative: one cannot, prior to the experience, know what it will be like (and what things will be like for one) post-experience. ${ }^{21}$ Despite not knowing exactly about the outcome for having children, we still have a rough estimation of what life will be like with a child. We have a good sense that the child will demand some of our resources, that we will have to attend to the child's needs, and that we may have to forgo our own desires in order to preserve the child's life. We have a good sense of what is possible and what is likely in the domain of human experience. Whilst we do not know exactly what we will be like after the baby is born, we can have a pretty good idea of what life will be like.

The same cannot be said of the transformative experience between a mortal life and an immortal body-bound life. The body-bound immortal will not grow old as mor-

\footnotetext{
${ }^{20}$ Burley (2009); Nussbaum (1989).

${ }^{21}$ Paul (2014).
} 
tals do. The face and body they see in the mirror is the same one day-in and day-out, and their sensory experience, likewise, will not change in the ways that ours does from one year to the next.

Carving nature at its joints might not convince the critic that mortals and immortals are fundamentally different. The body-bound immortal is near enough to the mortal such that the critic might contend that the experiences of the immortal are not a matter of difference in kind but a matter of difference of degree. We can infer from our own experiences what it would be like to be an immortal, particularly a body-bound immortal because the experiences of both are closely connected and are different only insofar as the degree of experience one possesses.

Distinguishing between the experience of an immortal and those of mortals cannot be just a matter of degree. When we think of what sort of things could differ in degree, we probably think of alterations in colour saturation or heat intensity. In summer, heat is more intense than it is in winter. If the child bears down softly on the red crayon, leaving more white paper to show through, the colour will look less like red and more like pink. Qualitative experiential states fail to possess the property of intensity. Sure, there might be situations where one visually senses something more intensely, such as watching a comrade be shot or the blue sky absent any haze. The sky's colour saturation or the intensity of living through a battle in war come in degrees, but the qualitative experience is something someone has or does not have.

We should avoid the temptation to believe that an immortal's subjective experience differs in degree from our own sensory experience given that our own mortality presents certain epistemic limits. Beglin has argued that we should not relinquish our mortality because body-bound immortality fails to live up to Williams' unthinkability condition: 'Nothing less will do for eternity than something that makes boredom unthink$a b l e^{\prime} .{ }^{22}$ We cannot divorce the threat of boredom from the question of what immortality would be like, and we have not the epistemic grounds to judge what an immortal life would be like. At least one of Beglin's reasons has to do with our temptation for believing that the subjective experiences of an immortal life is merely an extension of our mortal life. We should avoid the assumption that what our subjective experiences are now extends into an immortal life. It is generally unclear how a mortal could appreciate the value of an immortal's subjective qualitative states without being able to comprehend what they would be like. Subjective experiences form a fundamental part of our mortal life in a way that they may, or may not, for the immortal.

To imagine what it is like to be immortal is to imagine being a creature well beyond the confines of our own skin. Even if we limit ourselves to conceptualising bodybound immortals, it is too distant from our own subjective experiences.

We are somehow imagining creatures who are meant to be like us but who are not embodied in the way we are, who pass through no stages of life, who know nothing of the characteristic challenges, triumphs, or disasters associated with any of those stages, who need not work to survive, who do not undergo danger or

${ }^{22}$ Beglin (2017); Williams (1973): 87. 
overcome it, who do not age or face death or the risk of it, who do not experience the reactions of grief and loss that the death of a loved one inspires, and who never have to make what they can of the limited time and opportunities that they have been given..$^{23}$

There is very little in the body-bound immortal's subjective experience that resembles our own, especially when we consider the temporal elements of our decision-making about life events, choosing a mate or changing careers. None of these would bother the body-bound immortal. Mere mortals cannot appreciate that to slip the surly bonds of earth is to touch the face of God. Everything about how we organise our life is predicated upon its transitoriness. The impermanence of the mortal life gives it a narrative arc.

In this section, I have called into question whether the conscious experience we possess as mere mortals lacks a property the subjective qualitative experience an immortal might have. To my mind, the substantive difference in the two kinds of experience is largely a result of the difference in the stability of immortality and mortality. We ought not to judge the experiences of a permanent being who could live forever from the perspective in which we are now confined. Coming to terms with who that person is and how that person views the world may be so different from the person I am now that it is impossible to conceive of what it is like to be immortal. Just as we fail to understand how animals like bats, cows, and ants experience the world, we cannot know how weyears hence-will view the world. Given that for us to conceive of an immortal life we must project onto it our own view of what it is like to be us, and what our conscious experience is like, and given that an immortal life may not be anything like the life we live, we cannot conceive of what it is like to be immortal.

\section{Objections}

That the conscious experience of an immortal is inconceivable does not arise without controversy and it is the purpose of this section of the paper to summarise potential criticisms of my position. By no stretch of the imagination will I be able to anticipate and resolve all possible objections; rather, I limit myself to some of the most troubling problems the position must address.

\subsection{Facts vs. Point-Of-View}

First, a critic might argue that my conclusion has no support because we cannot rule out that there is a fact of the matter regarding whether the conscious experience I have now resembles the conscious experience of my future body-bound immortal self. It may not be possible for us to know how many stars there are in the universe. We may never possess the capability to count the total number of stars in the universe. When someone says that "there is an odd number of stars in the universe," the fact is true of a universe in which the number of stars is odd. Nagel anticipates this objection when he writes:

${ }^{23}$ Scheffler (2013): 98-99. 
My realism about the subjective domain in all its forms implies a belief in the existence of facts beyond the reach of human concepts. Certainly it is possible for a human being to believe that there are facts which humans never will possess the requisite concepts to represent or comprehend. Indeed, it would be foolish to doubt this, given the finiteness of humanity's expectations. After all, there would have been transfinite numbers even if everyone had been wiped out by the Black Death before Cantor discovered them. ${ }^{24}$

According to this objection, our inability to conceive of the immortal life does not rule against the fact that there is a conscious experience associated with immortal life. There is a what it is like or qualitative experience exemplified in a life without end. Even if it is something with which we are unfamiliar now, we might become familiar with it in the future when immortals prevail on earth or we ourselves become these immortals, such as in the case of EM.

Nagel seemingly admits, however, that the critic's response is too quick. There might be certain facts that have been, are now, and always will be inaccessible to us humans, no matter how long we live and no matter what we discover about the facts. Nagel says:

But one might also believe that there are facts which could not ever be represented or comprehended by human beings, even if the species lasted for ever - simply because our structure does not permit us to operate with concepts of the requisite type. This impossibility might even be observed by other beings, but it is not clear that the existence of such beings, or the possibility of their existence, is a precondition of the significance of the hypothesis that there are humanly inaccessible facts. (After all, the nature of beings with access to humanly inaccessible facts is presumably itself a humanly inaccessible fact. $)^{25}$

Ultimately, then, there might be a fact of the matter about what it is like to be immortal and what it is like to be a bat, but what I am considering here, and what Nagel tried to point out in his own essay is that there is a fact (or facts) associated with the particular point of view of the immortal with which we are not remotely able to comprehend or to conceive.

\subsection{The Future Is Not What It Used To Be}

Second, a critic might contend that my argument suggesting that we cannot conceive of our own future mental life presupposes that our future self living a body-bound immortal life has radically different experiences of the world than the sensory experiences of the person who lives in the present. If my argument is correct, so the critic will argue, then it is not my own mental life that experiences the future but the mental life of someone else, some distinct future self. According to the objection, it does not seem to be true that anyone other than myself will be living the future life. Therefore, we ought to reject my argument that a punctuated immortal life is something we cannot conceive.

${ }^{24}$ Nagel (1979): 171.

${ }^{25}$ Ibidem. 
The critic has a point, but I do not believe it is one we ought to find compelling. When we were children, we formed beliefs about what our future occupation would be. Perhaps Smith wanted to be a lawyer. Whatever it is that Smith preferred at an earlier time in life might not have come to pass later in life. Smith, instead, becomes a manager of a fast-food chain restaurant. When Smith reflects upon it, the thought might be that as a young child Smith might not have been able to conceive of becoming a manager of a fast-food restaurant. Nothing about the decision to become the manager may have crossed young Smith's mind. It seems, then, that young Smith and older Smith are two distinct individuals, with distinct preferences and with distinct goals, experiencing the world in fundamentally different ways.

The critic might respond that my assessment is unfair because it fails to account for the evolution of Smith's preferences and the story we might be able to tell of how young Smith's penchant for good food served quickly led Smith to augment such a desire by pursuing a career in the fast-food industry. Moreover, perhaps Smith developed a disdain for studying. This would rule out becoming a lawyer because it requires a great deal of study. The evolution of Smith's interests would give the critic some leverage in a negative response to the argument I have outlined.

Of course, it seems that even Nagel has already anticipated a response we might provide to the evolution worry raised above. He writes:

Experience itself ... does not seem to fit the pattern. ... Certainly it appears unlikely that we will get closer to the real nature of our human point of view and striving for a description in terms accessible to beings that could not imagine what it was like to be us. If the subjective character of experience is fully comprehensible only from one point of view, then any shift to greater objectivity---that is, less attachment to a specific view point---does not take us nearer to the real nature of the phenomenon: it takes us farther away from it. ${ }^{26}$

To suppose that we grasp the subjective phenomenal character of conscious experience of some future state because we can understand how that future state developed from an earlier sensory experience seems to confuse the 'real nature' of subjective experience with our ability to abstract our thoughts away from our occurrent conscious states. For the objector to be correct, the response would require us to think not in terms of the phenomenological experience of some future self but in terms of how life events have altered over the course of a lifetime.

\subsection{Perry on 'Other Organisms'}

Finally, a critic might be tempted to argue that an immortal human's conscious experience could not possibly differ from our own experience. As John Perry (2001) has pointed out, there is a marked distinction between arguing that one's experience is different from another's experience and showing that something lacks a property that another entity has. He writes:

${ }^{26}$ Ibidem: 173. 
It is not enough to show that the properties we discover about $a$, thought about in one way, are quite different than those we associate with $b$, thought about in another way. We must show that $a$ clearly lacks a property $b$ has. Somewhat paradoxically, the more unlike $a$ and $b$ seem to be at first glance, the harder this may be to show. In particular, one has to keep in mind a fact that seems at first quite odd. Although the truth of the statement " $a=b$ " requires something pretty important of $a$ and $b$, it does not require much of anything about " $a$ " and " $b$," other than that there is a single thing to which they both refer. " $a$ " does not need to be definable in terms of " $b$," or to have been introduced in terms of " $b$," or to involve properties that supervene on those that " $b$ " involves, or vice versa. In this sense, identity is a very weak relation. ${ }^{27}$

I have tried to emphasise this point in my argument, i.e., that it is not enough to show that differences exist in the perceptions the young body-bound immortal and the older body-bound immortal has. There is, according to my argument, a property that the bodybound immortal has that we do not. For one, the body-bound immortal is immortal. Since we fail to possess the property of immortality and it seems an integral part of being immortal, I believe that should be enough to show that one entity lacks a property the other possesses and that that property is fundamental enough to challenge the soundness of Perry's potential criticism.

\section{Conclusion}

I have outlined three potential criticisms that recommend against the view that one cannot conceive of the immortal's subjective character of conscious experience. Projecting our own views of subjective conscious experience onto the hypothetical life of an immortal seems like a promising way of comprehending whether we would find such an interminable life appealing or not. What I have attempted to argue in this paper is that the projection is inconceivable. Similarly, given that an immortal like may not have the "what-it-is-like" qualia we typically associate with our own life experiences, we cannot conceive of what it is like to be immortal. ${ }^{28}$

\section{References}

Altshuler, R. (2015), "Immortality, Identity, and Desirability," [in:] Immortality and the Philosophy of Death, M. Cholbi (ed.), Rowman and Littlefield, Lanham (MD): 191-203.

Beglin, D. (2017), “Should I Choose to Never Die? Williams, Boredom, and the Significance of Mortality," Philosophical Studies 174 (8): 2009-2028.

\footnotetext{
${ }^{27}$ Perry (2001): 6.

${ }^{28}$ I would like to thank Dave Beisecker, Donald Bruckner, Mark Ernste, Luciana Garbayo, Kristen Hine, John McClure, Stephen Sullivan, and especially Marc Moffett for conversations and correspondence leading to a draft of this paper, and I am especially grateful for the constructive feedback received from Justine Kingsbury and two referees to help shape the manuscript into what it is.
} 
Beisecker, D. and Ulatowski, J. (Unpublished MS), "The Tedium of Immortality and the Exhaustion of Science," University of Nevada, Las Vegas, 18pp.

Bortolotti, L. and Y. Nagasawa. (2009), "Immortality Without Boredom," Ratio 22 (3): 261-277.

Bostrom, N. (2008), "Why I Want To Be A Posthuman When I Grow Up," [in:] Medical Enhancement and Posthumanity, B. Gordijn and R. Chadwick (eds.), Springer, Dordrecht: 107-137.

Bruckner, D. (2012), "Against the Tedium of Immortality," International Journal of Philosophical Studies 20 (5): 623-644.

Burley, M. (2009), "Immortality and Meaning: Reflections on the Makropulos Debate," Philosophy 84 (4): 30-44.

Chalmers, D. (1996), The Conscious Mind, Oxford University Press, Oxford.

Chappell, T. (2007), "Infinity Goes Up On Trial: Must Immortality Be Meaningless?” European Journal of Philosophy 17 (1): 30-44.

Fischer, J.M. (1994), "Why Immortality Is Not So Bad," International Journal of Philosophical Studies 2 (2): 257-270.

Fischer, J.M. (1997), "Death, Badness, and the Impossibility of Experience," Journal of Ethics 1: 341-353.

Gems, D. (2003), “Is More Life Always Better?" The Hastings Centre Report 33: 31-39.

Johnston, M. (2010), Surviving Death, Princeton University Press, Princeton (N.J.).

Mezei, B. (2017), "Realist Phenomenology and Philosophy of Religion: A Critical Reflection," Logos $i$ Ethos 44: 47-70.

Nagel, T. (1979), “What Is It Like To Be A Bat?” [in:] Mortal Questions, T. Nagel (ed.), Cambridge University Press, Cambridge: 165-180.

Nussbaum, M. (1989). "Mortal Immortals: Lucretius on Death and the Voice of Nature," Philosophy and Phenomenological Research 50(2): 303-351.

Paul, L.A. (2014), Transformative Experience, Oxford University Press, Oxford.

Paul, L.A. (2015), "What You Can't Expect When You're Expecting," Res Philosophica 92 (2): $1-23$.

Perry, J. (2001), Knowledge, Possibility, and Consciousness, The MIT Press, Cambridge (MA).

Preston, T. and S. Dixon. (2007). "Who Wants To Live Forever? Immortality, Authenticity, and Living Forever in the Present," International Journal for Philosophy of Religion 61: 99-117.

Rosenberg, Jay. (2006), “Reassessing Immortality: The Makropulos Case Revisited," [in:] The Good, The Right, Life and Death: Essays in Honor of Fred Feldman, K. McDaniel, J.R. Raibley, R. Feldman, and M.J. Zimmerman (eds), Ashgate Publishing Company, Burlington (VT): 227-240.

Scheffler, S. (2013), Death and the Afterlife, Oxford University Press, Oxford.

Smith, B. (1997), "Realistic Phenomenology," [in:] Encyclopedia of Phenomenology, L. Embree (ed.), Springer, Dordrecht: 586-590.

Steele, H. (1976), “Could Body-Bound Immortality Be Liveable?” Mind 85 (339): 424-427.

Williams, B. (1973), "The Makropulos Case: Reflections on the Tedium of Immortality," [in:] Problems of the Self, B. Williams (ed), Cambridge University Press, Cambridge: 82-100. 